Claves. Revista de Historia, Vol. 5, $\mathrm{N}^{\circ} 9$

Montevideo, julio - diciembre 2019

(pp. 145 - 173) ISSN 2393-6584

\title{
Memoria e identidad en el relato histórico de los intelectuales afrouruguayos del Centenario (1925- 1930)
}

Memory and identity in the historical narrative of AfroUruguayan intellectuals of the Centenary (1925-1930)

Hernán Rodríguez

Universidad de la República

\section{DOI: https://doi.org/10.25032/crh.v5i9.7}

Recibido: 28/09/2019

Aprobado: 04/12/2019

Resumen. El artículo propone un análisis del modo en que los intelectuales afrouruguayos usaron el pasado para producir las representaciones identitarias que dieron forma a la comunidad negra que imaginaron en el contexto de las celebraciones por el Centenario de la Independencia de Uruguay (1925-1930). A partir del estudio del manuscrito de Lino Suárez Peña fechado en 1924 y de los ensayos de Elemo Cabral y Marcelino Bottaro publicados en 1934 en la antología reunida por Nancy Cunard, se analizan las formas en que los intelectuales afrouruguayos dialogaron con una narrativa histórica y un imaginario nacionalista que exaltaba la excepcionalidad uruguaya basada en la homogeneidad racial de origen europeo y minimizaba la presencia de la población negra y su aporte a la formación de la nación.

Palabras clave. Afrouruguayos, identidad, memoria, nación.

Abstract. The article proposes an analysis of the way in which Afro-Uruguayan intellectuals used the past to produce the identity representations that shaped the black community they imagined in the context of the celebrations for the Centenary of the Independence of Uruguay (1925-1930). From the study of the manuscript written by Lino Suárez Peña in 1924 and the essays of Elemo Cabral and Marcelino Bottaro published in 1934 in the anthology gathered by Nancy Cunard, the article 
analyzes how Afro-Uruguayan intellectuals spoke with a historical narrative and a nationalist imaginary that exalted Uruguayan exceptionalism based on racial homogeneity of European origin and minimized the presence of black people and their contribution to the formation of the nation.

Keywords. Afro-Uruguayans, identity, memory, nation.

\section{Introducción}

Los años de los centenarios de la Independencia de 1925 y 1930 en Uruguay fueron momentos de síntesis y celebración del imaginario nacionalista que ambientaron la disputa por el pasado y la reformulación del relato histórico de la nación. Los intelectuales afrouruguayos buscaron participar de este espacio de negociación abierto por el marco conmemorativo, reclamando un lugar en la narrativa nacional que reconociera el aporte de los africanos y sus descendientes a la formación del país y modificara los modos en que estos eran representados en el imaginario colectivo.

Estos intelectuales formaban parte de una generación de afrouruguayos nacidos a finales del siglo XIX, muchos de los cuales provenían de los departamentos del interior del país y se radicaron en Montevideo en las primeras décadas del siglo Xx. Eran jóvenes escritores, artistas y periodistas, en general autodidactas, con una mejor posición socio-económica que la mayoría de la población negra gracias al ingreso a la burocracia estatal, a la práctica de algún oficio o profesión universitaria, o a su trabajo al servicio de familias acomodadas. Fueron el relevo de una generación de letrados negros que en el último tercio del siglo XIX desarrolló una importante actividad periodística y asociativa en Montevideo y en Buenos Aires que aspiraba a formar una comunidad letrada negra en el Río de la Plata. Esta tradición letrada fue continuada y ampliada en la primera mitad del siglo $\mathrm{xx}$, transformando a la prensa negra de Uruguay en una de las más importantes de América Latina. ${ }^{1}$ El volumen de

\footnotetext{
${ }^{1}$ Entre 1872 y 1901 se publicaron al menos once periódicos en Montevideo, aunque se conservan ejemplares de seis de ellos: La Conservación (1872), El Progresista (1873), La Regeneración (2. ${ }^{\text {a }}$ época, 1884-1885), El Periódico (1889), La Propaganda (1893-1895) y El Eco del Porvenir (1901). En estas publicaciones se mencionan otros diarios (La Crónica, El Porvenir, El Sol, El Tribuno y La Regeneración en su 1. ${ }^{\mathrm{a}}$ época) de los que no se conservan ejemplares. Entre 1911 y 1948 los afrouruguayos publicaron otros 16 periódicos. En Montevideo: La Verdad (1911-1914), La Propaganda (1911-1912), La Vanguardia (1928-29), Nuestra Raza (1933-1948), Periódico del PAN (1937-1938), Ansina (1939-1942), Renovación (1939-1940), El Erial (1942), Rumbo Cierto (1944-1945) y Revista Uruguay (1945-1948). En el resto del país: Nuestra Raza (1. ${ }^{\mathrm{a}}$ época, 1917) en Maldonado, Acción
} 
esta prensa evidencia la relevancia de este sector intelectual afrouruguayo que, a pesar de constituir un grupo minoritario, pudo sostener en el tiempo una fecunda labor periodística que estuvo acompañada de una intensa actividad en el ámbito social y cultural.

Al igual que en el siglo XIX, los intelectuales afrouruguayos del Centenario valoraron la palabra escrita como una herramienta de representación comunitaria fundamental para producir un discurso sobre sí mismos. El presente trabajo no propone un estudio comprensivo de este discurso, sino que busca arrojar luz sobre el modo en que los intelectuales afrouruguayos articularon memoria e identidad en su relato del pasado, examinando tres fuentes escritas por algunos de los principales referentes de esta generación: Lino Suárez Peña, Marcelino Bottaro y Elemo Cabral.²

Lino Suárez Peña (1890-1942) fue uno de los intelectuales afrouruguayos más importantes de la primera mitad del siglo Xx. Durante varios años se desempeñó como portero del Ministerio de Instrucción Pública hasta que en 1936, luego de varias postergaciones, fue ascendido a ordenanza de la Fiscalía de Hacienda. ${ }^{3}$ La estabilidad económica que brindaba la incorporación a la burocracia estatal, le permitió desplegar una importante labor periodística, primero como administrador del periódico La Verdad (1911-1914) y luego como colaborador de la revista Nuestra Raza (1933-1948). Cumpliendo con el encargo de instituciones a las que no menciona, en 1924 escribió un manuscrito titulado «Apuntes y datos referentes a la raza negra en los comienzos de su vida en esta parte del Plata» con el objetivo de reseñar el aporte negro a la formación de la nación4. Este manuscrito fue utilizado por Suárez Peña como base para la publicación en 1933 de un folleto titulado La raza

(1934-1935) y Orientación (1941-1945) en Melo, Rumbos (1938-1945) y Democracia (1942-1946) en Rocha y El Peligro (1934) en Rivera.

2 Otros de los intelectuales afrouruguayos destacados del período fueron Salvador Betervide (abogado y periodista, director de La Vanguardia y fundador del Partido Autóctono Negro, PAN), Isabelino José Gares (poeta, dramaturgo y redactor de La Vanguardia), el poeta Pilar Barrios y su hermano Ventura Barrios (fundadores de la revista Nuestra Raza), Mario R. Méndez (caricaturista de Nuestra Raza y primer candidato a diputado del PAN), Iris Cabral y Maruja Pereyra (periodistas y activistas por los derechos de las mujeres), Victoriano Rivero (redactor de La Verdad), Isidoro Casas Pereyra (poeta y director de la revista Ansina), Carlos Cardozo Ferreira (poeta y redactor de La Vanguardia y Nuestra Raza), entre otros.

3 Nuestra Raza, Montevideo, 23 de agosto de 1936, p. 37.

4 El manuscrito se encuentra en un cuaderno con dos portadas y 21 hojas escritas y sin paginar en el Archivo Pablo Blanco Acevedo del Museo Histórico Nacional de Uruguay. A los efectos de este trabajo se modificó la ortografía del original y se realizó una paginación para referenciar las citas al documento excluyendo las dos páginas de portada. 
negra en el Uruguay. Novela histórica de su paso por la esclavitud que, a pesar de algunas modificaciones, reproducía en lo esencial el relato de 1924. Alex Borucki señala que es probable que el manuscrito de Suárez Peña sea el primer ensayo de reflexión histórica escrito por un afrouruguayo sobre la esclavitud y la sociabilidad afrodescendiente. Su relevancia radica, además, en el trabajo de rescate de la memoria oral de ancianos de origen africano en Montevideo y no en ser un testimonio de un ex-esclavo como han sugerido algunos investigadores. (Borucki $313)^{5}$

Entre 1931 y 1933 la escritora y activista británica contra el racismo Nancy Cunard realizó una compilación de artículos sobre la situación de la población negra en distintas zonas del mundo que fue publicada en 1934 con el título Negro. Los dos artículos sobre los negros en Uruguay fueron escritos por Elemo Cabral («The Negro Race in Uruguay») y Marcelino Bottaro («Rituals and «Candombes»). ${ }^{6}$ Según George Reid Andrews, ambos artículos fueron incluidos en la antología reunida por Cunard gracias a la intermediación del escritor uruguayo Ildefonso Pereda Valdés que procuró poner en contacto a los intelectuales afrouruguayos con el activismo antiracista mundial (Andrews 2011 138).7

Tanto Elemo Cabral (1887-1969) como Marcelino Bottaro (1883-1940) fueron activos promotores del asociacionismo y de la prensa negra de Montevideo durante las primeras décadas del siglo Xx. Al igual que Suárez Peña, acceder a un empleo en los escalafones más bajos del sector público (Cabral fue portero del Museo Histórico Nacional y Bottaro fue funcionario de la Dirección de Aduanas), aunque representaba escasos ingresos, les otorgó cierta seguridad económica para realizar una intensa actividad periodística, cultural y política. Elemo Cabral fue director y editor de la

\footnotetext{
5 Borucki, Alex, «Entre el aporte a la identidad nacional y la reivindicación de las minorías. Apuntes sobre los afrodescendientes y la esclavitud en la historiografía uruguaya", Historia Unisinos, n. ${ }^{\circ} 10$, 2006, p. 313. Borucki se refiere al confuso título del libro de Jorge Gallardo Un testimonio sobre la esclavitud en Montevideo. La memoria de Lino Suárez Peña y al libro Buenos Aires negra del arqueólogo argentino Daniel Schávelzon en el que se emplea el manuscrito como testimonio de un exesclavo de Montevideo.

${ }^{6}$ Los artículos fueron publicados en inglés. Las citas realizadas a lo largo del trabajo son de traducción mía.

7 Pereda Valdés fue uno de los iniciadores de los estudios históricos sobre afrodescendencia en Uruguay y formó parte de los intelectuales que en las décadas del veinte y del treinta enfrentaron los proyectos de blanqueamiento de las sociedades americanas y militaron para inscribir a los afrodescendientes en las historias nacionales (Andrews, George Reid. Negros en la nación blanca: historia de los afro-uruguayos, 1830-2010. Montevideo: Linardi y Risso, 2011, p. 138).
} 
revista Nuestra Raza durante 15 años, integró el Centro de Intelectuales, Artistas, Periodistas y Escritores Negros (Ciapen) creado en $1935 \mathrm{y}$ fue miembro fundador del PAN en 1936.8 Marcelino Bottaro fue redactor del periódico La Propaganda, colaborador de La Vanguardia y de Nuestra Raza e impulsó varias organizaciones de la comunidad negra como el Comité Pro-Repatriación de los Restos de Ansina y la Agrupación Pro-Centro de la Raza, fundada en 1911 con el objetivo de contar con una institución cultural que nuclease a los afrouruguayos, proyecto que se concretó finalmente en 1934 con la creación de la Casa de la Raza. 9

A partir del análisis del manuscrito de Suárez Peña y de los artículos de Bottaro y Cabral, este trabajo propone un estudio del relato del pasado elaborado por los intelectuales afrouruguayos del Centenario. En particular, se analizan los modos en que usaron la historia para dar fundamento a las representaciones colectivas que promovieron, en un contexto de celebración de una nación que se imaginaba blanca y europea.

\section{La nación imaginada y celebrada en el Uruguay del Centenario}

Benedict Anderson entiende que las naciones son comunidades imaginadas en las que la «imagen de comunión» que «vive» en la mente de individuos que se desconocen entre sí es el basamento de la identificación colectiva.(1993 23) «La magia del nacionalismo - escribe Anderson- es la conversión del azar en destino», en el sentido en que las naciones se imaginan como comunidades a las que la narrativa nacional les confiere un «pasado inmemorial» $\mathrm{y}$ un «futuro ilimitado» en común (29). Esta «narrativa de la nación» proporciona un conjunto de historias, símbolos y rituales que representan las experiencias compartidas que dan significado a la nación.(Hall 1992 381). De esta forma, los individuos se proyectan en la trama de un relato colectivo que construye el mito de los orígenes y de la continuidad de la nación, presentando su evolución como el único destino posible, de modo tal que sus integrantes se perciban a sí mismos como su lógico desenlace. (Balibar 1997 136, 145).

\footnotetext{
8 El PAN fue uno de los tres partidos políticos negros creados en América Latina en el siglo XX. Los otros dos fueron el Partido Independiente de Color fundado en Cuba en 1908 y el Frente Negra Brasileira fundado en Brasil en 1930.

9 Nuestra Raza [Montevideo], jun. 1934: 11.
} 
El historiador uruguayo Gerardo Caetano afirma que en Uruguay los imaginarios colectivos han tenido un peso decisivo en el proceso de construcción de la identidad nacional. En las primeras décadas del siglo Xx, en particular en los años del Centenario, se reafirmó el primer imaginario nacionalista en formación desde fines del siglo XIX. Más que fundación de un segundo imaginario hubo resignificación del primero, generándose una síntesis de la identidad uruguaya que se expresó en un «sistema de relatos, símbolos y mitos» articulados en un «cuerpo de significaciones colectivas».10 El imaginario del Centenario debió poner el foco en la integración del adentro, demandada tanto por el nuevo aluvión de inmigrantes europeos como por un proyecto de desarrollo nacional impulsado por el reformismo batllista. En consecuencia, la prioridad fue crear un «modelo endointegrador de base uniformizante», fundamentado en un discurso oficial que privilegiaba la «meta del crisol de identidades» (Caetano 2010 162). Con esta matriz integradora, se cimentaron lo que Caetano denomina las notas más perdurables del imaginario nacional: el culto a la excepcionalidad uruguaya en América Latina, el cosmopolitismo de perfil eurocéntrico, la exaltación del tono optimista de la convivencia, el elevado grado de integración de la sociedad sobre la base de la «fusión de culturas» y el orgullo por la homogeneidad racial de la población, entre otras (163). Sin embargo, tras el aparente éxito que representaba la formación de una «nacionalidad inclusiva» sin grandes marginaciones, se escondía la generación de «estereotipos sociales y culturales» que ambientaron «la sanción a la diferencia» (162-163).

10 Caetano, Gerardo. "Ciudadanía y nación en el Uruguay del Centenario (1910-1930) La forja de una cultura estatista». Iberoamericana, vol. 39, 2010, p. 163. Caetano sostiene que el marco conmemorativo en el que se procesó la síntesis de este imaginario propició el debate en torno a los modelos de nación y de ciudadanía que se manifestó, por ejemplo, en la controversia por la fecha de la independencia. Si bien distintos actores participaron en esta polémica, los partidos políticos tuvieron un rol central. Por un lado, el Partido Colorado, en especial el batllismo, defendió la fecha de la jura de la primera Constitución (el 18 de julio de 1830), optando por una celebración más orientada al futuro que al pasado y que privilegiaba la meta de la reforma moral. En cambio, el Partido Nacional defendió el 25 de agosto de 1825 (fecha de la aprobación de la ley de independencia por la Asamblea de la Florida), más orientada a privilegiar los «referentes del pasado» y la tradición (169 y 170). Según Carlos Demasi, la polémica entre un Centenario de tono conservador y otro de tono reformista dio origen a una "visión consensuada» del pasado que ha perdurado en la memoria colectiva, pero desvinculada del conflicto de proyectos del que surgió (Demasi, Carlos. La lucha por el pasado. Historia y nación en Uruguay (1920-1930), Montevideo: Ediciones Trilce, 2004, 17). En esta dirección, Demasi señala que el pasaje de una sociedad que se imaginaba «condenada a la guerra civil permanente» a una sociedad que veía a los partidos políticos compartiendo el poder, ambientó una reinterpretación del pasado que buscó crear una «tradición de coexistencia política» y una «identidad común» capaz de amortiguar las diferencias entre los partidos y reforzar la separación con los países vecinos $(13,17)$. 
¿Qué lugar ocuparon los afrouruguayos en este imaginario nacionalista celebrado en los años del Centenario? Una de las notas más perdurables que se crearon respecto a la población negra fue la relativa a su escasa presencia en el país, lo que reafirmaba la pretendida homogeneidad racial de origen europeo de los uruguayos. Según Balibar, en la construcción de la identidad nacional cumple una función clave la «etnicidad ficticia», es decir, una ficción que proyecta a la nación en el pasado y en el futuro como «comunidad natural», dotada de una homogeneidad racial y cultural que asegura tanto su continuidad histórica como la identidad de intereses de sus miembros $(149,154)$. En Uruguay, esta «etnicidad ficticia» construida sobre la base de la ausencia indígena, la escasez de población negra y la masiva concurrencia de inmigración europea, constituyó uno de los motivos de orgullo que pautaban la singularidad de la nación en el contexto americano. Así lo expresaba uno de los textos nacionalistas promovidos desde el Estado en los años del Centenario:

El Uruguay es el único país de América que no tiene población indígena, siendo casi todos sus habitantes de raza blanca. No se le presentan, pues, los inquietantes problemas del indio o del negro, que tanto preocupan a la generalidad de las naciones americanas. (Nin y Silva 1930 10)

La imaginación de una nación blanca y europea también implicó la creación de un relato que no le reconocía a la población negra aportes significativos a la formación del país. En algunos casos, este aspecto era expresado por contraste, enumerando las virtudes aportadas por la población blanca. Horacio Araújo Villagrán, por ejemplo, en su libro elocuentemente titulado Estoy orgulloso de mi país, atribuía la «superioridad» de Uruguay en América a la ausencia del «problema de razas» que le permitió crear un «tipo nacional» caracterizado por ser «activo, noble, franco, hospitalario, inteligente, fuerte y valiente y de raza blanca en su casi totalidad» (1929 80). Esto implicaba, a su vez, que la población no blanca representaba los rasgos contrarios: pasividad, deshonestidad, debilidad, cobardía, etc. En otras ocasiones, eran señalados los aspectos negativos introducidos por la población negra. Blanco Acevedo, por ejemplo, remarca el modo en que su «idiosincrasia peculiar» había influido sobre los «hijos de familia» que «no oirían cosa digna de imitarse» de sus criados negros salvo supersticiones, brujerías e inmoralidades (Blanco, 1936 98). Por lo tanto, concluía Blanco Acevedo, su aporte al 
«carácter colectivo» de la nación había sido escaso «si se exceptúan las manifestaciones que infelizmente ha tenido [...] hacia la «guaranguería», la falta de educación, la ausencia de escrúpulos [...] la indisciplina en el trabajo o la perversión de los sentimientos morales». (99)

La certeza de constituir una «raza selecta» alimentó el tono optimista con el cual las elites uruguayas percibían el futuro del país. En las primeras décadas del siglo $\mathrm{xx}$, el arribo masivo de inmigrantes prometía integrar a la población afrodescendiente en un crisol de identidades europeas, consolidando así la homogeneidad racial «excepcional» de Uruguay en América. Desde las páginas del Libro del Centenario, publicación oficial de 1925 destinada a «compendiar la marcha victoriosa del país», se defendía esta visión que auguraba la dilución progresiva de los afrodescendientes en una nación blanca:

Puebla el Uruguay la raza blanca, en su totalidad de origen europeo...La pequeña proporción de raza etiópica, introducida al país por los conquistadores españoles, procedente del continente africano, a fin de establecer la esclavitud en estas tierras, disminuye visiblemente hasta el punto de constituir un porcentaje insignificante...Por otra parte, sus características originales han sufrido, por el clima, circunstancias del medio ambiente y por mezcla de la sangre europea, modificaciones fundamentales. (López 1925 43)

La narrativa nacionalista del Libro del Centenario, además de minimizar la presencia afrodescendiente en el país y de reafirmar la meta del blanqueamiento por medio de la «sangre europea», reproducía un relato del pasado que señalaba a los «conquistadores españoles» como los responsables del tráfico de esclavos. De este modo, se colocaba fuera de los límites de la nación al culpable de la esclavitud, y se expiaba la culpa de los criollos negando su participación en una actividad cruel e inhumana. El recuerdo de la esclavitud también fue utilizado para destacar otro de los aspectos que explicaban la supuesta excepcionalidad uruguaya en América: el trato más «humanitario» que habrían recibido los esclavos en la Banda Oriental en comparación con otras zonas del continente. «Es de creer - afirma Blanco Acevedoque incorporados a las familias, [los esclavos] gozasen de buen trato por el interés presumible de sus dueños, a fin de mantenerlos en buen estado de salud» (110). Esta imagen de la esclavitud que resaltaba la «benevolencia» de los amos, pretendía fundamentarse en el hecho de que la mayoría de los esclavos habían desempeñado 
tareas en el ámbito doméstico y, por lo tanto, se habían integrado a la vida familiar recibiendo un trato más benigno. ¿Cómo dialogaron los intelectuales afrouruguayos con esta narrativa nacionalista que celebraba la escasez de afrodescendientes en Uruguay, relativizaba el sufrimiento de sus antepasados esclavizados y minimizaba sus contribuciones a la formación del país?

\section{Entre el recuerdo y el olvido: el aporte negro a la nación}

En el contexto de una comunidad nacional que celebraba su homogeneidad racial europea e impelía a los «otros» internos a redefinir sus formas de identificarse, la generación de intelectuales afrouruguayos del Centenario buscó en el pasado argumentos que legitimaran su identificación como uruguayos y elaboró un relato histórico que destacaba los aportes de la población negra a la formación del país. Este relato, además de incorporar las contribuciones de los africanos y sus descendientes en la narrativa histórica de la nación, pretendía modificar las representaciones del imaginario colectivo que asociaban a los negros con la servidumbre, la pasividad, la ignorancia, la inmoralidad y la superstición.

Lino Suárez Peña inicia su manuscrito explicitando las razones que motivaron su escritura y describiendo su tarea como la de revolver los «escombros del pasado»: «entrando en el terreno de mi cometido - escribe- hecho una mirada retrospectiva, revolviendo los escombros del pasado». ${ }^{11}$ Esta imagen remitía al carácter parcial de la reconstrucción histórica y transmitía la impresión de un pasado fragmentado e irrecuperable en todo su espesor, del cual solo quedaban «escombros» con los que comenzar una tarea de recomposición de la memoria. Para Suárez Peña, parte de esta tarea consistía en ordenar la información disponible sobre la «vida primera» de los negros en «esta parte del Plata», rescatando del «injustificado ostracismo» las contribuciones que hicieron al progreso del país y que tenían un «arraigo profundo en el espíritu nacional».12 Este «espíritu» debía «inspirar»a las autoridades de la educación pública para intensificar «su acción a fin de que todas estas cosas sean recogidas en la historia nacional». ${ }^{13}$ Desde su perspectiva, al incorporar estos aportes en la enseñanza de la Historia, además de realizarse un acto de justicia, se estaba

\footnotetext{
${ }_{11}$ Suárez Peña, Lino. Apuntes y datos referentes a la raza negra en los comienzos de su vida en esta parte del Plata. Jun. 19, 1924. Manuscrito. Museo Histórico Nacional, Montevideo, p. 1.

12 Suárez Peña, 19.

13 Suárez Peña, 19-20.
} 
contribuyendo a enriquecer la «tradición múltiple» del país. De este modo, Suárez Peña apelaba a la meta del «crisol de identidades» promovida por el imaginario nacionalista, como argumento para inscribir los aportes de los afrodescendientes en el relato histórico de la nación.

¿Cuáles eran estos aportes que, en palabras de Suárez Peña, estaban cubiertos por el «sudario del olvido»? En primer lugar, el sacrificio realizado por los soldados negros que combatieron en las guerras de la independencia. El recuerdo de la actuación militar de sus antepasados ocupó un lugar central en el discurso de los intelectuales afrouruguayos del siglo Xx que, de este modo, retomaban una de las notas principales del relato histórico de los letrados negros del siglo XIX. Así lo expresaba Suárez Peña en 1924:

El negro...presta su juramento ante el altar sagrado de la patria...A partir de ahí demás está enumerar su participación heroica en todos los hechos de armas americanos que cubrieron de gloria el regio temple del Pueblo Oriental. Su lealtad y hombría queda justificada desde el día que la patria les confió su defensa hasta que postraron ante ella al ibérico altivo león. ${ }^{14}$

En su relato del pasado, los intelectuales afrouruguayos no solo activaron la estrategia del recuerdo, sino que también manejaron los olvidos. Al exaltar la «participación heroica» en la defensa de la patria contra el «ibérico altivo león», Suárez Peña recordaba a los soldados negros que lucharon en las filas de la patria, pero olvidaba a los que lucharon junto a los «enemigos de la nación» integrando, por ejemplo, los regimientos de libertos que combatieron bajo el estandarte de la Corona española y portuguesa. Al evocar la participación de los soldados negros en las guerras de la independencia se buscaba vincularlos a los momentos fundacionales de la nación. Además, se intentaba abrir un espacio de representación en el imaginario nacional en el que los africanos y sus descendientes aparecieran asociados a valores positivos como la lealtad, el heroísmo y la valentía. Esta representación de los soldados negros como héroes anónimos que habían sacrificado sus vidas por la libertad de la nación también es planteada por Elemo Cabral:

El sacrificio de los negros[...] es innegable [...] En las tropas, luchando por la libertad, sirvieron como carne de cañón. Se puede decir que no hubo un solo movimiento que

\footnotetext{
${ }^{14}$ Suárez Peña, 5-6.
} 
involucre los destinos de las provincias en el que el valiente soldado negro anónimo no participara...Siguió al Patriarca Artigas y lo abandonó solo cuando estaba en su lecho de muerte en la pobreza y el exilio, en Paraguay, 1850. (1934 519)

Cabral reproduce un relato similar al de Suárez Peña pero incorpora un elemento novedoso: los soldados negros que acompañaron fielmente a Artigas en la adversidad del exilio y de la pobreza15. Esta exaltación de los lazos de lealtad hacia Artigas (que solo la muerte podía disolver) poseía una gran carga simbólica que contribuía a sellar el vínculo de los negros con la nación (representada en la persona de su héroe máximo). La imagen de lealtad al «Padre de la Patria» encontrará su síntesis en la construcción de la figura de Ansina como el fiel soldado artiguista que siguió al prócer en su exilio en Paraguay. Esta representación, ausente en el relato histórico de los letrados negros del siglo XIX, será impulsada por los intelectuales afrouruguayos del Centenario que vieron en el vínculo Artigas-Ansina la expresión simbólica de la lealtad del soldado negro (representado por Ansina) hacia la nación (representada por Artigas). ${ }^{16}$

Tanto Elemo Cabral como Marcelino Bottaro tuvieron un rol protagónico en la lucha por el reconocimiento oficial de la figura de Ansina. Cabral promovió su reivindicación histórica desde las páginas de la revista Nuestra Raza, de la cual fue director. En una nota publicada en 1935, por ejemplo, se anunciaba la repatriación de sus restos desde Paraguay como el retorno del «héroe olvidado», del «consecuente y fiel compañero del Patriarca Uruguayo», cuyas «cenizas descansarán junto a las de su jefe y compañero de exilio».17 Por su parte, Bottaro solicitó a las autoridades municipales de Montevideo que designaran con su nombre una calle del Barrio Reus al Sur y colocaran una placa en su homenaje, e integró el comité que impulsó la repatriación de los restos de Manuel Antonio Ledesma (identificado en ese entonces

\footnotetext{
${ }_{15} \mathrm{Si}$ bien Lino Suárez Peña no menciona a Artigas en su manuscrito, es significativo que eligiera fecharlo el 19 de junio de 1924, coincidiendo con la fiesta patria en la que se conmemora el natalicio del prócer.

${ }^{16}$ La construcción de Artigas como el héroe fundador de la nacionalidad oriental, iniciada en el último tercio del siglo XIX, llegó a su momento culminante y celebratorio en los años del Centenario. En 1923, por ejemplo, se inaugura la estatua ecuestre de Artigas en la Plaza Independencia, principal monumento dedicado al "prócer» en Montevideo. En este marco es que los intelectuales afrouruguayos buscan incorporar la figura de Ansina a la narrativa nacional.

17 Nuestra Raza, Montevideo, 26 de setiembre de 1935, p. 26. Entre 1939 y 1942 se publicó en Montevideo una revista anual con el título Ansina. Manuel Antonio Ledesma, destinada a homenajear y promover el reconocimiento de Ansina.
} 
como Ansina), ${ }^{18}$ aspiración que se concretó finalmente en octubre de $1938 .{ }^{19} \mathrm{El} 18$ de mayo de 1939 (coincidente con la fecha de la batalla de Las Piedras), sus restos fueron velados junto al monumento a Artigas en la plaza Independencia en una ceremonia que contó con amplia participación de la comunidad afrouruguaya. ${ }^{20} \mathrm{En}$ 1942 el gobierno uruguayo presidido por el colorado Alfredo Baldomir impulsó una serie de festejos para conmemorar los 100 años de la abolición de la esclavitud, decretada en 1842 por el gobierno colorado de Fructuoso Rivera. Asociada a este ciclo de celebraciones, el 18 de mayo de 1943 se hizo la inauguración de un monumento en homenaje a Ansina en Montevideo, realizado por el escultor uruguayo José Belloni. En este se representa a un Ansina sentado y empuñando una lanza, delante de una reproducción de la pintura de Juan Manuel Blanes Artigas en el puente de la Ciudadela, acompañada de la leyenda: «Juntos en el exilio. Juntos en la eternidad. Juntos en su patria para gloria de un pueblo agradecido» (Scuro Somma 2008 95). De este modo, se materializaba en el bronce la imagen del leal soldado artiguista que, si bien reconocía el aporte de los soldados negros y los vinculaba a los orígenes de la nación junto a su héroe máximo, contribuía a reproducir el estereotipo del negro fiel y sumiso al servicio del blanco.

Suárez Peña finaliza su manuscrito reivindicando el aporte de los negros al país en otros dos aspectos: el intelectual y el deportivo. Respecto al primero, se refiere al surgimiento dentro de la comunidad negra de "personas de reconocida inteligencia», entre los que destaca a los doctores Francisco Rondeau y Martín Estevarena, quienes supieron «honrar el nombre de su raza» desempeñándose como «jurisconsultos» en el «foro nacional». ${ }^{21}$ El reconocimiento de Suarez Peña a la actuación de los intelectuales afrouruguayos que, como él, eran los menos visibles en el imaginario nacional, implicaba cuestionar representaciones arraigadas en la memoria colectiva que asociaban a los negros con los sirvientes o los soldados. De este modo, los intelectuales afrouruguayos del Centenario continuaron con una tarea

\footnotetext{
${ }_{18} \mathrm{El}$ apodo Ansina refiere al menos a dos personas distintas: Joaquín Lenzina y Manuel Antonio Ledesma. Este último fue el utilizado por el Estado para oficializar la imagen de Ansina como símbolo de fidelidad al héroe (Gortázar, Alejandro, «Ansina cun héroe en clave afro-uruguaya?». Los héroes fundadores. Perspectivas desde el siglo XXI. Comps. C. Demasi y E. Piazza. Montevideo: CEIU, Universidad de la República, 2006, p. 123).

19 Sobre el rol de Bottaro en la reivindicación de la figura de Ansina ver Nuestra Raza, Montevideo, 30 de mayo de 1941, p. 93.

${ }^{20}$ Nuestra Raza, Montevideo, 30 de mayo de 1939, p. 69.

${ }^{21}$ Suárez Peña, 20
} 
iniciada por los periódicos negros del siglo XIX, que dedicaban sus columnas a felicitar el avance en los estudios de los miembros destacados de la comunidad. Estos letrados negros solían ser presentados como modelos de honradez, constancia y esfuerzo que demostraban el grado de progreso e ilustración alcanzado por la población negra. ${ }^{22}$

Por otro lado, respecto al plano deportivo, Suárez Peña reivindica la actuación de tres futbolistas negros que fueron protagonistas de los primeros triunfos de la selección uruguaya de fútbol: Juan Delgado, Isabelino Gradín y José Leandro Andrade. ${ }^{23}$ De esta forma, apelaba a tres figuras que, a través de los éxitos deportivos, habían logrado el reconocimiento de la sociedad uruguaya de la época y cierta trascendencia internacional. ${ }^{24}$ Es interesante la utilización que Suárez Peña hace del fútbol para dar fundamento a la identificación con la nación. En Uruguay, el fútbol ha sido una «fuente inspiradora» del imaginario nacional contribuyendo a la construcción de la identidad de los uruguayos. Los estadios de fútbol son escenarios en los cuales el país se vuelve visible y concreto, el público se apropia de los símbolos nacionales y transforma a los futbolistas en «héroes nacionales» y a los triunfos en «gestas deportivas» (Alfaro 1992 26, 127). Suárez Peña escribe en un momento fundacional de este vínculo entre fútbol e identidad nacional en Uruguay que, en sus orígenes, también tuvo un componente racial. Por ejemplo, el mismo día en que está

${ }_{22}$ Rodríguez, Hernán. «Revolviendo los escombros del pasado: usos del pasado e identidad en el discurso de los letrados negros de Montevideo (1872-1901)». Tesis de maestría, FHCE, Universidad de la República (Uruguay), 2018, p. 63.

Ver, por ejemplo, los artículos en homenaje a los abogados Juan C. Díaz y Francisco Rondeau publicados respectivamente en La Regeneración, Montevideo, 8 de marzo de1885, p. 13 y $L a$ Propaganda, Montevideo, 18 de noviembre de 1894, p. 64. Sobre el reconocimiento a Rondeau en la prensa negra del siglo XX ver Nuestra Raza, Montevideo, marzo de 1934. p. 8 y agosto de 1934, p. 13.

${ }_{23}$ Juan Delgado e Isabelino Gradín integraron la selección uruguaya de fútbol que se consagró campeona en el Campeonato Sudamericano de 1916. Este hecho fue advertido por la prensa chilena de la época que, luego de la victoria de Uruguay sobre Chile, denunció que la selección uruguaya había incluido en su equipo a «dos africanos». Gradín fue campeón sudamericano de fútbol nuevamente en 1917 y se destacó también en el atletismo, obteniendo varias medallas a nivel sudamericano. José Leandro Andrade fue protagonista de la selección uruguaya de fútbol que ganó tres Campeonatos Sudamericanos (1923, 1924 y 1926), dos medallas olímpicas de oro (París, 1924 y Ámsterdam, 1928) y la primera Copa del Mundo (Montevideo, 1930) (Gutiérrez Cortinas, Eduardo, «Los negros en el fútbol uruguayo", 100 años de fútbol, vol. 10, 1970, pp. 227-233).

24 Gradín fue homenajeado por el poeta peruano Juan Parra del Riego en la poesía Polirrítmico dinámico a Gradín, jugador de fútbol, texto declamado por la actriz argentina Berta Singerman el 28 de julio de 1924 en el Teatro Solís, con la presencia del propio Gradín entre el público (Carina Blixen. Isabelino Gradín: testimonio de una vida. Montevideo: Ediciones del Caballo Perdido, 2000, p. 99). Por su parte, Andrade había deslumbrado al público parisino en 1924, ganándose el elogio de la prensa francesa de la época que lo reconoció como la «maravilla negra» (Gutiérrez Cortinas, «Los negros en el fútbol uruguayo», ob. cit., p. 237). 
fechado su manuscrito (19 de junio de 1924), la revista Mundo Uruguayo publicó una portada que celebraba la medalla de oro obtenida diez días antes por la selección de fútbol en los Juegos Olímpicos de París con la leyenda: «Por el prestigio de la Patria y el porvenir de la Raza».25 El triunfo olímpico era utilizado como una oportunidad para exaltar a la nación y al carácter selecto de su raza cuando, paradójicamente, uno de los futbolistas decisivos para la obtención del torneo había sido Andrade. Es en este contexto que Suárez Peña decide destacar la participación de los futbolistas negros, presentando sus éxitos deportivos como logros de la nación e interpretando su actuación como una valiosa contribución a la «gloria de la Patria», con la que habían dejado «muy en alto el hermoso pendón de sus antecesores». ${ }^{26}$

Por último, los intelectuales afrouruguayos del Centenario tomaron distancia de una de las representaciones más arraigadas en el imaginario colectivo: la asociación de la población negra con la música y la danza del candombe. A diferencia de los intelectuales negros de fines del siglo XIX, este alejamiento del candombe no obedecía a la intención de romper con el pasado africano, sino que apuntaba a su revalorización. Suárez Peña y Bottaro coinciden en señalar que la música y la danza auténticamente africanas habían desaparecido en la segunda mitad del siglo XIX y, por consiguiente, no debía considerarse al actual candombe como una herencia cultural africana sino como su deformación. Suárez Peña sostiene que los «bailes originales», a través de los cuales sus antepasados «rememoraban las costumbres de su país natal» al ritmo de «compases llenos de aliento africano», fueron desapareciendo a impulsos de la «evolución del tiempo» que decretó su «cese natural». ${ }^{27}$ Por su parte, Bottaro atribuye la degeneración de los rituales africanos a un proceso de mercantilización que terminó transformando al candombe en un negocio guiado por «sórdidos intereses» (1934 521). Como consecuencia, los sitios donde se practicaba candombe dejaron de ser los lugares en los que sus antepasados habían dado «libre expresión a sus cantos» («emotivos poemas de reminiscencias de África»), para convertirse en «tugurios indignos», repletos de «vulgar concupiscencia» y movidos por el «solo fin del lucro» y la «tentación del éxito fácil», que constituían un «insulto para todos los elementos de la raza africana» (521-22). De esta forma, concluye Bottaro, la «delicada y simple armonía de las danzas

\footnotetext{
${ }_{25}$ Mundo Uruguayo [Montevideo], jun. 19, 1924: 284.

${ }^{26}$ Suárez Peña, 21.

${ }_{27}$ Suárez Peña. 4 y 8.
} 
africanas [...] se fueron a la basura», enterrando las «tradiciones africanas en los bien conocidos Piringundines» (522).

Es interesante la importancia que Bottaro asigna a los letrados negros del siglo XIX en la desaparición de los rituales africanos. En este sentido, responsabiliza a los jóvenes negros de Montevideo de «cierta cultura» que en 1872 publicaron el semanario La Conservación y dedicaron sus «columnas editoriales» a cuestionar las «prácticas de sus mayores», desacreditándolas como «farsas» que no obedecían a «ningún principio lógico» (521). Según Bottaro, el resultado de este «grito de guerra» de la prensa negra fue la ruptura de la «conexión entre los negros africanos y montevideanos», que terminó provocando la "pérdida del exacto conocimiento» de los cultos originales (522). Por lo tanto, el candombe como «forma degenerada» no tenía mayor valor para Bottaro y la música y danza africanas, que eran lo valioso para él, se habían perdido. Es por esto que finaliza su artículo cuestionando a los estudiosos sobre el «folclore negro» que, a su juicio, habían interpretado de forma equivocada el candombe al considerarlo un fruto de la herencia cultural africana. La argumentación de Bottaro no promueve una ruptura con lo africano, como la prensa negra del siglo XIX, sino una revalorización de lo que, a su entender, es lo auténticamente africano y, en cierta media, formaba parte de los «escombros» irrecuperables a los que aludía Suárez Peña.

En conclusión, los intelectuales afrouruguayos del Centenario no reivindicaron el candombe como aporte africano y buscaron inscribir a los negros en el imaginario nacional destacando su contribución como soldados, intelectuales y futbolistas. ¿En qué medida este discurso cuestionaba las bases de la narrativa histórica de la nación?

\section{Entre la reproducción y el cuestionamiento del relato histórico de la nación}

Los intelectuales afrouruguayos pretendieron participar en el espacio de negociación del relato de la nación que abrió el marco conmemorativo de los Centenarios, reclamando la incorporación del aporte negro a la formación del país. En su relato histórico incorporaron las premisas principales de la narrativa nacionalista que solo era cuestionada en la medida en que excluía a la población negra. En este sentido, reprodujeron el esquema básico de un relato que explicaba de 
forma lineal el desarrollo de la nación en tres momentos fundamentales: la dominación (Colonia), la liberación (Revolución) y la formación del Estado (República); e interpretaron la historia de los africanos y sus descendientes a la luz de cada una de estas etapas, de modo tal que la Colonia representó la esclavitud, la Revolución la lucha por libertad y la República la integración como ciudadanos libres.

En primer lugar, el relato histórico de los intelectuales afrouruguayos reafirmaba la centralidad de la noción de colonia en la explicación de la dominación española en América y señalaba a España como la responsable de la trata y la esclavización. Cabral, por ejemplo, inicia su artículo describiendo la esclavitud como «un régimen infame de origen claramente español», impuesto en América con el objetivo de mejorar la «baja condición» de los «nativos de las colonias españolas». Con este propósito, escribe Cabral, «apareció, con el sello oficial de España, la mancha que ciertamente era una negación del "espíritu civilizador" de los señores del continente». (1934 518). Suárez Peña también inicia su manuscrito señalando la responsabilidad del «régimen colonial» español en el tráfico de esclavos. Su relato comienza en el año 1791 en referencia a la Real Cédula que dispuso la libre introducción de esclavos por el puerto de Montevideo. Con esta decisión de la «Corona Española», afirma Suárez Peña, «se inocula ese flagelo llamado esclavitud».28 Además, cuando alude a los protagonistas del tráfico de esclavos, solo menciona a una compañía española (la Compañía de Filipinas) y «olvida» a los comerciantes montevideanos involucrados en dicho comercio. Ambos relatos cargan a los españoles con la responsabilidad de la esclavitud y soslayan el rol que tuvieron las elites criollas en la reproducción del sistema esclavista. Al colocar al esclavista fuera de los límites de la nación, el relato de los intelectuales afrouruguayos presentaba una visión del pasado que favorecía la reconciliación entre los descendientes de los esclavos y los descendientes de los amos de esclavos: ambos habían sido víctimas de la misma dominación colonial impuesta por España.

Esta lectura de la esclavitud se diferenció de la interpretación planteada por parte de la prensa negra del siglo XIX que señaló a los «hombres blancos» (no solo a los «españoles») como los responsables de la esclavización de sus antepasados. En estos términos lo expresaba una editorial de La Conservación en 1872:

\footnotetext{
28 Suárez Peña, 1-2.
} 
No esperemos[...] la protección de los hombres blancos porque de ellos tan solo recibiremos farsas y engaños [...] Unámonos como hermanos de una raza que ha sido sacrificada bárbaramente en el pasado [...] Reclamemos las glorias que nuestra raza ha alcanzado en los campos del honor, reclamemos la sangre derramada de la frente de nuestros padres, y no miremos atrás [...] pero llevemos siempre en la memoria el recuerdo de nuestros padres que fueron víctimas de los que hasta hoy son nuestros enemigos. 29

Esta interpretación de la esclavitud reforzaba la identificación racial al representar un «nosotros negro» (los descendientes de los esclavizados) opuesto a un «otro blanco» (los descendientes de los esclavistas), y socavaba la posibilidad de pensar un presente de reconciliación a partir de la identificación con la nación (Rodríguez 151). Recordar la esclavitud en términos de blancos esclavistas y negros esclavizados implicaba exponer un pasado de enfrentamiento que atentaba contra la creación de un «nosotros» nacional. La distancia temporal con el pasado interpretado parece ser central para entender las diferencias entre las lecturas de la esclavitud realizadas por los intelectuales afrouruguayos en el siglo XIX y en el siglo XX. Para los intelectuales afrouruguayos del Centenario la esclavitud ya no es continuidad en el presente de la explotación del «hombre blanco», sino una afrenta que cae sobre la España colonialista. Por lo tanto, si bien recuerdan un pasado incómodo para la narrativa de la nación, construyen un relato en el que predomina un tono conciliador que promueve la integración de los afrodescendientes en la comunidad nacional.

Por otro lado, los intelectuales afrouruguayos del siglo xx compartieron con los del siglo XIX el cuestionamiento a un relato histórico que resaltaba el trato humanitario recibido por los esclavos en el Río de la Plata. Cabral critica duramente esta «tradición» según la cual sus antepasados habrían sido «bien tratados» y plantea una visión que subraya la inhumanidad de la esclavitud. "Nuestros ancestros», afirma Cabral, fueron víctimas de un «vil comercio» que los convirtió en «piezas de mercancía vendidas públicamente», condenándolos a ser un «elemento servil» de los «elementos españoles» y a vivir en una «precaria condición social». (518-19). En esta dirección, Cabral denuncia los abusos sexuales que sufrió la mujer esclava por parte del «señor y amo» que «siempre complacía su apetito más exigente», y advierte sobre el «prejuicio racial de los historiadores blancos» que se niegan a reconocer la

${ }^{29}$ La Conservación [Montevideo] nov. 10, 1872: 15. 
frecuencia con la que se produjo el «cruce de negros y blancos».30 También Bottaro enfatiza el «cruel destino» que sufrieron sus antepasados, adquiridos por la violencia y transformados en «mercancía humana» para luego ser «explotados como cosas» (520). En términos similares, Suárez Peña remarca la barbarie de la esclavitud, describiendo «la tristeza inmensa que amargaba el ánimo de aquellos pobres seres», que habían sido brutalmente «arrancados del seno de sus seres más queridos» y tratados «con la misma indiferencia que si se tratase de comprar una vaca o un caballo». $3^{1}$

El relato histórico de los intelectuales afrouruguayos, si bien cuestionaba la narrativa nacionalista al poner énfasis en el sufrimiento de sus antepasados esclavizados, también reproducía algunas imágenes que representaban a los negros como sirvientes fieles y sumisos. Cabral, por ejemplo, subraya en su artículo el modo en que los esclavos negros «sirvieron a las familias con la acostumbrada fidelidad de la raza».(519). Y Suárez Peña, por su parte, destaca la «paciencia e indiferencia» con la que soportaron «todo ese cúmulo de vejámenes», preguntándose por qué no imitaron a «la indómita raza del charrúa» (su «hermana en infortunio») que con orgullo y rebeldía se enfrentó al «tirano». $3^{2}$ En el contraste con los rasgos positivos que le asigna a los charrúas (coraje, rebeldía, ferocidad), Suárez Peña refuerza los rasgos negativos que, a su juicio, aún caracterizaban a los negros de su tiempo (indiferencia, pasividad, mansedumbre) y que, desde su perspectiva, era necesario modificar.

En segundo lugar, los intelectuales afrouruguayos reprodujeron el relato de la independencia de la narrativa nacionalista, que postulaba a la nación como una entidad preexistente destinada a constituirse en Estado independiente. De este modo lo expresa Suárez Peña en su manuscrito:

...corren los años tejiendo los acontecimientos históricos...que traen aparejados como consecuencia lógica la caída del virreinato español en ambas márgenes del Plata y con

\footnotetext{
$3^{30}$ Es probable que Cabral se estuviera refiriendo a Pablo Blanco Acevedo, al que cita en otra parte del texto y que, por lo tanto, formaba parte de las lecturas que utilizó para escribir su artículo. En este sentido, Blanco Acevedo afirma en El Gobierno Colonial (obra citada por Cabral): «La cruza de blancos con negros o con indios, o de éstos con los segundos, fue la excepción y el tipo del mulato o del mestizo no abundó, en virtud, principalmente, de la situación inferior reconocida a los individuos cuya ascendencia de sangre no se considerase absolutamente limpia» (98).

${ }^{31}$ Suárez Peña, 2-3.

${ }^{2}$ Suárez Peña, 3.
} 
ésta la rotura de vínculos hércules que atan a estas jóvenes naciones a los dictados de la madre España: surge en toda su plenitud, el sol que alumbra la mañana del 28 de Febrero del año 1811 y un grito de libertad puebla el espacio, es el dado por un puñado de patriotas que ansiosos por liberarse del dominio que les imponía España [...] La simiente había sido depositada en terreno fecundo y estaba llamada a dar su fruto obligado.33

En este fragmento, Suárez Peña reproduce los supuestos sobre los cuales se edificó la historia nacionalista: la preexistencia de la nación («jóvenes naciones»), el carácter predestinado y fatalista de su emancipación (una «consecuencia lógica», «un fruto obligado»), la voluntad temprana de independencia (el 28 de febrero de 1811)34 y la exaltación de su obtención («el sol que alumbra la mañana») en tanto representaba la liberación del dominio español. En su relato hay una valoración negativa de la Colonia, que condenó a la esclavitud, y una valoración positiva de la Nación, que concedió la libertad. (Borucki 313). Para Suárez Peña, esta libertad se justificaba por el compromiso patriótico que habían demostrado los soldados negros en los campos de batalla. En este momento de su relato, los negros dejan de ser representados como esclavos pasivos y sumisos, y son representados como valientes y leales soldados que sacrificaron su vida por la libertad de la nación. Hubiera sido un acto de «lesa injusticia», concluye Suárez Peña, negar los «valores morales conquistados por el negro» y mantener la «institución inhumana de la esclavitud».35

¿Cómo resolvieron los intelectuales afrouruguayos el desfasaje entre las fechas de independencia (ya fuera esta 1825 o 1830) y la fecha de abolición de la esclavitud (1842)?36 Por un lado, Suárez Peña vincula el decreto de abolición de 1842 con los episodios de 1825 al presentarlo como el último eslabón de un proceso iniciado por la labor legislativa de la Asamblea de la Florida, que en setiembre de 1825 había

\footnotetext{
33 Suárez Peña, 5-6.

34 Suárez Peña reproduce el relato oficial que inicia la «Revolución Oriental» el 28 de febrero de 1811 con el episodio conocido como "Grito de Asencio»: la toma de Mercedes y Soriano por un pequeño grupo armado que se alzó contra las disposiciones fiscales adoptadas por el gobierno de Montevideo para combatir el movimiento revolucionario liderado por Buenos Aires. A diferencia de lo que plantea Suárez Peña, en 1811 el levantamiento en la Banda Oriental fue contra Montevideo y no contra España, manteniendo la fidelidad a Fernando VII hasta 1813 en que se definió por la independencia.

35 Suárez Peña, 6.

${ }^{36}$ La abolición de la esclavitud se produjo en la coyuntura de la Guerra Grande por medio de dos decretos, uno del gobierno colorado de Montevideo (12 de diciembre 1842) y otro del gobierno blanco del Cerrito (28 de octubre de 1846), ambos con el propósito de incorporar a los libertos a los respectivos ejércitos. Los intelectuales afrouruguayos recuerdan solo la «abolición colorada» de 1842, continuando con la posición de la prensa negra del siglo XIX vinculada a caudillos colorados y a militares negros que habían combatido en la Defensa de Montevideo.
} 
reconocido la libertad de todas las personas nacidas en territorio oriental. ${ }^{37}$ Aunque la legislación de 1825 se refería a los hijos de los esclavos y no establecía la libertad de los ya existentes, para Suárez Peña fue una «obra noble» que estuvo guiada por la misma intención que el decreto de 1842: «realizar el bien por el bien mismo».38 «A partir de esta lógica - escribe Suárez Peña - la obra estaba incompleta; le faltaba su complemento necesario y lo obtuvo el 12 de diciembre de 1842».39 En consecuencia, la nación otorgó la libertad a los esclavos en dos tiempos enlazados simbólicamente por lo que él denomina el «espíritu» de los «hombres del año 25 y 42».40 De esta forma, Suárez Peña cerraba la brecha entre los dos momentos históricos y, en el marco de los debates por el Centenario de la Independencia, adscribía a la fecha de 1825 destacando su importancia en el proceso de abolición de la esclavitud.

Por su parte, Cabral también buscó integrar a los negros en el relato de los episodios de 1825 pero destacando su aporte como soldados. En este sentido, recuerda su participación en la «invasión de los 33 bajo el mando de Lavalleja» ( «fortalecida por dos de nuestros hombres»41) y en la guerra contra el Imperio de Brasil. Los soldados negros, escribe Cabral, «siguieron todo el movimiento, derramando su sangre en los campos de Sarandí, de Ituzaingó y de Las Misiones...hasta lograr el triunfo final, la libertad y la independencia de la patria». (519). Es interesante cómo Cabral retoma una de las imágenes más recurrentes en el discurso de la prensa negra del siglo XIX: la «sangre derramada» por los soldados negros en los campos de batalla. Esta imagen constituye una de las notas más perdurables en el relato del pasado de los intelectuales afrouruguayos debido a la poderosa carga simbólica que contiene: al tiempo que exalta el sacrificio de los soldados negros que dieron su vida por la libertad de la patria, contribuye a reforzar los lazos con la nación al sellarlos con la sangre de sus antepasados (Rodríguez 39).

\footnotetext{
37 Suárez Peña se refiere a la Asamblea de la Florida como «la primera entre sus similares de América» en declarar la libertad de los hijos de esclavos, olvidando la «libertad de vientres» sancionada el 31 de enero de 1813 por la Asamblea Constituyente reunida Buenos Aires.

$3^{8}$ Suárez Peña, 6.

39 Suárez Peña, 6.

40 Suárez Peña, 19.

${ }^{41}$ Estos eran Dionisio Oribe (criado de Manuel Oribe) y Joaquín Artigas (criado de Manuel P. Artigas, sobrino de José Artigas). Según Cabral, su «retrato fue legado a la posteridad por el lápiz de Juan Manuel de Blanes», en referencia a la pintura El Juramento de los 33 Orientales. Sin embargo, en el cuadro de Blanes ambos aparecen situados al fondo de la escena sin que su rostro sea visible, evidenciando el relegamiento de los negros en las representaciones de la nación.
} 
Por otro lado, Cabral expresa una visión consensuada del proceso de independencia destacando, primero, la figura de Artigas como héroe fundador de la nación y reconociendo también el protagonismo de Lavalleja y de Rivera que, luego de apoyar la «noble empresa» de Artigas, «lucharon bajo la misma bandera de la libertad». (519). De este modo, no solo recurría a la figura de Artigas como imagen de concordia anterior a las divisiones partidarias, sino que, además, reproducía un relato en el que blancos y colorados (representados en las figuras de Lavalleja y Rivera) aparecían luchando juntos por un mismo objetivo: la libertad de la nación. En la misma dirección, Cabral intenta conciliar la fecha de 1825 (en la que la ley cambió la «situación como esclavos» de los «hijos de África») con la de 1830 (en la que la Constitución instauró un «régimen republicano» que «estableció claramente la libertad para todos los habitantes del territorio», sin reconocer «distinciones de clase»). (519). A pesar de la importancia que le atribuye a la Constitución como momento fundacional, Cabral reconoce que la «anterior situación del negro» continuó incambiada y no fue hasta la abolición de la esclavitud en 1842 que se consagró definitivamente la libertad en la República.

Ambos autores coinciden en su valoración del año 1842 como un año fundacional: el año que inicia la «vida nueva» para Suárez Peña, el año a partir del cual «comienza la evolución social de la raza» para Cabral. El año 1842 tiene un lugar central en su relato histórico como fecha simbólica que marcó el quiebre entre un pasado de esclavitud impuesta por la dominación española y un futuro de libertad concedida por la nación. Desde esta perspectiva, la abolición de la esclavitud representó el primer paso en el camino de la integración social de los negros como hombres libres e iguales. Así lo expresa Suárez Peña:

\footnotetext{
Ya no había esclavos [...] Era un pueblo realmente demócrata y el sol aparecía alumbrando a todos por igual; ya no había esclavos ni señores, era todo un abrazo fraternal. iSalve, santa igualdad, tú que riges con mano sabia y segura los dictámenes de la universal justicia...! Es indescribible la alegría que este fausto acontecimiento produjo en el ánimo de los pobres negros, con mayor intensidad en el de los viejos que aún no habían apreciado la satisfacción de saberse libres.42
}

Esta visión de la abolición omitía el contexto bélico de la Guerra Grande en el cual se había decretado y los efectos inmediatos que tuvo para los esclavos liberados:

${ }^{42}$ Suárez Peña, p. 7. 
el ejército para los hombres y el pupilaje para las mujeres y los niños. La interpretación de Suárez Peña se distanciaba así de la lectura de la abolición realizada por parte de la prensa negra del siglo XIX que, con una mayor cercanía al episodio, denunció la falsa promesa de igualdad y libertad que representaban la Constitución y las leyes, cuando en los hechos persistían prejuicios raciales que postergaban socialmente a los negros (Rodríguez 211).

La perspectiva de Suárez Peña se explica, además, por el contexto de enunciación de su discurso, un contexto de celebración de la unidad nacional que se fundaba en una visión consensuada del pasado. En este marco debe entenderse la valoración positiva que hace de la abolición de la esclavitud, así como la imagen de fraternidad entre los antiguos amos y los antiguos esclavos que domina su relato del período posterior a la abolición. Precisamente, el título que encabeza este apartado de su manuscrito («Vida nueva») transmite una imagen de armonía social, de «abrazo fraternal» propiciado por la nación. Es interesante la descripción que hace Suárez Peña de los lazos que persistieron luego de la abolición entre los exesclavos y sus antiguos amos. En este sentido, se refiere al «generoso desprendimiento» de los «viejos amos» que, en los «días festivos» como Navidad y día de Reyes, «cooperaban» con «cortinas, alfombras y otros enseres por el estilo» para el arreglo de los locales de las «naciones» africanas.43 Según Suárez Peña, luego de finalizadas las celebraciones «cada uno concurría a casa de sus viejos amos» hacia los cuales «nunca guardaron animosidad»: esta se había borrado «el mismo día que recibieron el bautismo de la libertad, pues nada hay que haga borrar tan pronto los rencores, como este acto de humana reparación».44

Según Alejandro Gortázar, Suárez Peña centra su relato en el sufrimiento de los esclavos elaborando «un discurso identitario marcado por la experiencia traumática de la esclavitud». (Gortázar 2005 70) Si bien comparto que su relato remarca la violencia de la esclavitud, pienso que prevalece un discurso de tono conciliador. A diferencia del relato de los letrados negros del siglo XIX que promovía la identificación racial a partir del recuerdo del pasado de esclavitud, el relato de Suárez Peña promueve la identificación nacional a partir del olvido de los odios pasados. El tono general de su discurso no es el de la raza sino el de la nación: España 
(y no los «hombres blancos») es la responsable de la esclavitud y la nación es la responsable de la liberación, el español es un esclavista cruel mientras que el uruguayo es un viejo amo generoso. De este modo, estructura su relato en torno a una visión igualadora de la nación que contenía una promesa de integración por encima de las distinciones raciales.

\section{El presente del pasado: la articulación entre memoria e identidad}

La memoria y la identidad se articulan a partir de la función selectiva de los relatos históricos, que manejan los recuerdos y los olvidos de acuerdo a la «evaluación del presente» y a la «proyección del futuro» (Ricoeur 2004 110, 115). En consecuencia, la memoria se moviliza al servicio de la identidad y estructura un relato que adjudica nuevos significados a los hechos del pasado, con el objetivo de dotar de sentido al presente y proyectar una visión del futuro (Demasi 2004 9, 14). Desde esta perspectiva, podemos preguntarnos acerca de las formas en que los intelectuales afrouruguayos usaron el pasado para responder a las exigencias de su presente y dar fundamento a la comunidad negra que imaginaron.

Por un lado, el relato histórico de los intelectuales afrouruguayos buscaba legitimar la integración de los afrodescendientes a la comunidad nacional promoviendo su representación como ciudadanos uruguayos. Con este objetivo, exigieron que los aportes de los africanos y sus descendientes a la construcción del país fueran reconocidos e incorporados por la Historia nacional. En consecuencia, elaboraron un discurso del pasado que, como ya se señaló, intentó vincular a sus antepasados con los momentos fundacionales de la nación exaltando, en especial, la lealtad demostrada por los soldados negros que combatieron en las guerras de independencia. Además, predominó en su discurso un tono conciliador que propiciaba el olvido de los odios pasados (que podían atentar contra la unidad de la nación) y la construcción de una imagen de fraternidad entre los antiguos amos y los antiguos esclavos luego de la abolición de la esclavitud.

Por otro lado, las lecturas del pasado de los intelectuales afrouruguayos estuvieron moldeadas por la necesidad de cohesionar a una comunidad negra que percibieron dividida y desorganizada. En este sentido, evocaron la tradición asociativa de las naciones africanas, revalorizándolas como ejemplos de 
organizaciones basadas en la cooperación y la ayuda mutua. Suárez Peña, por ejemplo, destaca los «estrechos lazos de fraternal mutualismo» de las salas de nación que, en caso de enfermedad, socorrían al paciente para «reparar la situación económica» con el aporte de los «escasos recursos pecuniarios» realizados con gran sacrificio por cada uno de sus miembros. 45 Este pasado de supuesta armonía entre las naciones africanas contrastaba con un presente de desunión y conflictos al interior de la comunidad negra. Entre las naciones, afirma Suárez Peña, no existían «esas represalias antagónicas que destruyen dentro de la generación actual cuanta iniciativa laudable se pone en tela de juicio, encaminada hacia elevar a los elementos de su raza».46 $\mathrm{El}$ recuerdo de las salas de nación como expresiones de fraternidad racial es utilizado por Suárez Peña para cuestionar la inacción de sus contemporáneos y alentarlos a dejar de lado las diferencias. De este modo, su mirada del pasado se articulaba con las preocupaciones que imprimía el presente: la necesidad de promover la solidaridad grupal para consolidar la unidad de la comunidad negra.

En la misma dirección apunta el planteo que hace Bottaro en su artículo. Para Bottaro los «sitios de asamblea», aunque dividieron a la población negra por el lugar de origen africano, representaron factores de unidad y cooperación cuya «piedra angular» era «la protección racial de sus adeptos» (520). En este punto es interesante notar la diferencia entre la perspectiva de los intelectuales afrouruguayos del último tercio del siglo XIX y los de comienzos del siglo Xx. Para los letrados negros del siglo XIX, que competían por el liderazgo de la comunidad negra con los referentes de las salas de nación, estas no representaban ejemplos de fraternidad racial, sino una herencia cultural africana de la que era preciso distanciarse para promover formas de organización «modernas», inspiradas en los modelos europeos adoptados por las élites uruguayas. (Rodríguez 70). En el siglo $\mathrm{xx}$, las naciones africanas ya no constituían un desafío al liderazgo de los intelectuales afrouruguayos. En cambio, estos dirigieron sus cuestionamientos hacia los «centros recreativos» que, guiados por el «egoísmo» y el «espíritu de lucro», habían «matado el espíritu combativo de varias generaciones» y desvirtuado el «ideal de una colectividad».47 En este contexto se enmarca el proyecto de creación de una Casa de la Raza impulsado por Bottaro, propuesta que se sumaba a las iniciativas que desde el siglo XIX venían intentando

45 Suárez Peña, 9.

${ }^{46}$ Suárez Peña, 8.

47 Nuestra Raza, Montevideo, 25 de octubre de 1936, p. 39. 
coordinar las acciones de las distintas organizaciones de los afrodescendientes. Para Bottaro, la fundación de una Casa de la Raza respondía, precisamente, a la necesidad de organizar un «foco cultural» que reuniera en una sola institución todas las «aspiraciones de acción colectiva», con el objetivo de realizar las «obras de solidaridad» necesarias para el «engrandecimiento común». De este modo, concluía Bottaro, resurgiría una «acción seria y disciplinada», capaz de terminar con el «caos de nuestra inorganización, haciendo factible la anhelada unión de toda nuestra raza». 48

A pesar de que rescataron la tradición asociativa de las salas de nación como antecedentes de organización y cooperación entre la población negra, los intelectuales afrouruguayos de inicios del siglo xx no expresaron una visión unívoca respecto a la herencia cultural de sus antepasados africanos. Bottaro, por ejemplo, destaca el marco de protección que las salas de nación otorgaban a sus miembros y el espacio de expresión que les ofrecía para conectarse con sus orígenes africanos, pero, a la vez, se refiere a ellas como «organizaciones pseudoreligiosas» que solían entregarse al «místico fervor» de «rituales misteriosos» $\mathrm{y}$ «leyendas absurdas y espeluznantes» (520). Suárez Peña también valora positivamente el «fraternal mutualismo» de las naciones africanas que evitaba los conflictos que dividían a la comunidad negra de su época pero, por otro lado, las describe como organizaciones supersticiosas que lograron unir a sus miembros «a pesar de su ignorancia manifiesta».49 $\mathrm{El}$ apartado de su manuscrito dedicado a las salas de nación (al que titula elocuentemente «Supersticiones de la ignorancia») lo inicia describiendo sus prácticas religiosas en estos términos:

En todas estas congregaciones existía la creencia religiosa, su temor a dios estaba por encima de todas las cosas [...] Ignorantes en absoluto, tejían toda clase de supersticiones acerca del amor de dios; el terror a los muertos era pánico; creían en la aparición de las ánimas benditas del purgatorio...para ellos no se hacía nada sin la voluntad de dios, sin esa voluntad no ingresaba nadie en sus instituciones.50

A pesar de referirse a las salas de nación como organizaciones religiosas en un tono negativo y describir sus rituales como una enumeración de supersticiones,

\footnotetext{
${ }^{48}$ Nuestra Raza, Montevideo, febrero de 1934, p. 7, y abril de 1934, p. 9.

49 Suárez Peña, 8.

50 Suárez Peña, 14-15.
} 
Suárez Peña se preocupa por aclarar que estos comentarios los hacía con respeto a sus antepasados africanos. Por ejemplo, al mencionar las «ceremonias mortuorias» de las naciones africanas, aclara que no lo motivaba un «ánimo de burla» hacia sus antepasados, sino que, «muy al contrario», se inclinaba «reverenciando lo que fueron sus costumbres y sus creencias».51 Bottaro también expresa admiración por los cultos africanos originales que, a su entender, eran expresión de la «gran alma de la raza africana». En este sentido, Bottaro también reconoce la relevancia que tuvieron estos rituales en los esfuerzos de sus antepasados por preservar los lazos con su África natal, a pesar de la dispersión de las culturas africanas provocada la trata y la esclavización. A través de su «fe y culto nativo», afirma Bottaro, «los negros reconstruían, lo mejor que podían, las costumbres que se pueden encontrar en los bosques del África Tropical». (520). En la misma dirección apuntan las palabras de Suárez Peña cuando se refiere al «deleite supremo» que sentían al «rememorar sus costumbres», proyectando «en su imaginación con indescifrable alegría, la visión de su África hermosa».52

Estas posiciones ambiguas que asumieron los intelectuales afrouruguayos hacia la herencia cultural de sus antepasados eran la manifestación de una relación conflictiva entre sus orígenes africanos y un presente que exigía modificar las formas de representarse para integrar la nación como ciudadanos uruguayos. Como afirma Andrews, desde la segunda mitad del siglo XIX las nuevas generaciones de afrodescendientes nacidas en Uruguay expresaron en su discurso esta «tensión entre el pasado africano y el presente y futuro de los modelos uruguayos heredados de Europa» (Andrews 2007 89). En el marco de las conmemoraciones del Centenario, los intelectuales afrouruguayos buscaron reforzar los lazos con la nación a partir de un relato histórico que exaltaba el recuerdo de sus antepasados africanos, pero representándolos como soldados valientes y leales que habían sacrificado su vida por la libertad de la patria. Así como el presente de desunión de la comunidad negra los llevó a reivindicar a las salas de nación como ejemplos de solidaridad grupal de los que había que aprender, el presente de una nación que se imaginaba blanca y europea los llevó a valorar negativamente las prácticas culturales africanas como ejemplos de superstición e ignorancia de los que había que tomar distancia. Además, de este modo, se postulaban a sí mismos como intelectuales que aspiraban a liderar a la 
comunidad negra guiándola por los caminos del progreso y de la educación lo cual implicaba, desde su perspectiva, dejar atrás el pasado africano para integrarse a la comunidad nacional como uruguayos.

\section{Conclusiones}

En las primeras décadas del siglo xx se consolidó en Uruguay un imaginario nacionalista que celebraba la homogeneidad racial de origen europeo de su población, minimizaba la presencia de afrodescendientes y les negaba aportes significativos a la construcción del país. En un contexto de renegociación del pasado abierto por las conmemoraciones del Centenario de la Independencia, los intelectuales afrouruguayos denunciaron el olvido de la Historia nacional y elaboraron un relato histórico que buscó incorporar a los africanos y sus descendientes a la narrativa de la nación, destacando el valor de sus contribuciones como soldados, intelectuales y futbolistas.

El relato histórico de los intelectuales afrouruguayos compartió con la narrativa nacionalista una concepción de la nación como entidad preexistente al Estado destinada a la independencia y una perspectiva lineal de su desarrollo histórico en tres etapas: la dominación colonial, la lucha revolucionaria y la fundación de la República. En su relato predomina una visión negativa de la Colonia que condenó a sus antepasados a la esclavitud y una valoración positiva de la República que les concedió la libertad. En este sentido, cuestionaron la imagen benigna de la esclavitud sostenida por la narrativa nacionalista y subrayaron el trato cruel e inhumano que sufrieron sus antepasados. De todos modos, al señalar a España como la responsable de la esclavitud, formularon un discurso que propiciaba la reconciliación entre los uruguayos a partir del olvido de los odios pasados. Desde su perspectiva, la abolición de la esclavitud dio inicio a una época de integración y fraternidad que alcanzaba su máxima expresión en el presente con la celebración de la unidad nacional en el marco del Centenario.

Los intelectuales afrouruguayos articularon memoria e identidad en su relato histórico buscando cohesionar a la comunidad negra en torno a un pasado compartido, y promover su integración a la comunidad nacional a partir de la exaltación de sus aportes a la nación. La tensión entre el pasado africano y el presente 
uruguayo se expresó en las posiciones ambiguas que sostuvieron respecto al legado cultural de sus antepasados. Por un lado, reivindicaron el mutualismo de las salas de nación como un antecedente de cooperación y solidaridad de la comunidad negra pero, por otro lado, descalificaron sus rituales y cultos religiosos como «supersticiones de la ignorancia» reñidas con la civilización y el progreso. La identificación con una nación que se imaginaba blanca y europea requería alejarse de aquellas prácticas culturales africanas que en el imaginario colectivo estaban asociadas con el atraso y la ignorancia, y formular un relato histórico que pudiera integrarse a la narrativa nacionalista a través, por ejemplo, de la exaltación de la lealtad de los soldados negros a la nación que, en los años del Centenario, se expresó simbólicamente en la reivindicación de la figura de Ansina como el fiel compañero de Artigas.

\section{Obras citadas}

\section{Bibliografía}

Alfaro, Milita, «Cultura subalterna e identidad nacional». Identidad nacional ¿mito, crisis o afirmación? Eds. Hugo Achugar y Gerardo Caetano. Montevideo: Ediciones Trilce, 1992.

Anderson, Benedict. Comunidades imaginadas. Reflexiones sobre el origen y la difusión del nacionalismo. Ciudad de México: Fondo de Cultura Económica, 1993.

Andrews, George Reid, «Recordando África al inventar Uruguay: sociedades de negros en el carnaval de Montevideo, 1865-1930». Revista de Estudios Sociales, vol. 26, 2007, pp. 86-104.

Andrews, George Reid. Negros en la nación blanca: historia de los afro-uruguayos, 1830-2010. Montevideo: Linardi y Risso, 2011.

Araújo Villagrán, Horacio. Estoy orgulloso de mi país. Montevideo: Sociedad Universal de Publicaciones, 1929.

Balibar, Etienne, «La forma nación: historia e ideología». Raza, Nación y Clase. Las identidades ambiguas. Eds. Immanuel Wallerstein y Etienne Balibar. Madrid: Iepala, 1997.

Blanco Acevedo, Pablo. El gobierno colonial en el Uruguay y los orígenes de la nacionalidad. Montevideo: Casa Barreiro y Ramos, 1936.

Blixen, Carina. Isabelino Gradín: testimonio de una vida. Montevideo: Ediciones del Caballo Perdido, 2000.

Borucki, Alex, «Entre el aporte a la identidad nacional y la reivindicación de las minorías. Apuntes sobre los afrodescendientes y la esclavitud en la historiografía uruguaya», Historia Unisinos, n. ${ }^{\circ}$ 10, 2006, pp. 310-320.

Bottaro, Marcelino, «Rituals and "Candombes"». Negro. Ed. Nancy Cunard. Londres: Wishart \& Co., 1934. 
Cabral, Elemo, «The Negro Race in Uruguay». Negro. Ed. Nancy Cunard. Londres: Wishart \& Co., 1934.

Caetano, Gerardo. «Ciudadanía y nación en el Uruguay del Centenario (1910-1930) La forja de una cultura estatista». Iberoamericana, vol. 39, 2010, pp. 161-175.

Demasi, Carlos. La lucha por el pasado. Historia y nación en Uruguay (1920-1930), Montevideo: Ediciones Trilce, 2004.

Gortázar, Alejandro, «Miradas cruzadas. La emergencia de los discursos sobre el aporte «afro» en Uruguay (1925-1945)». Estudios sobre la cultura afrorioplatense. Historia y presente. Eds. Arturo Bentancur et al. Montevideo: FHCE, Universidad de la República, 2005.

Gortázar, Alejandro, «Ansina ¿un héroe en clave afro-uruguaya?». Los héroes fundadores. Perspectivas desde el siglo XXI. Comps. C. Demasi y E. Piazza. Montevideo: CEIU, Universidad de la República, 2006.

Gutiérrez Cortinas, Eduardo, «Los negros en el fútbol uruguayo». 100 años de fútbol, vol. 10, 1970, pp. 219-238.

Hall, Stuart, «The Question of Cultural Identity». Modernity and Its Futures. Eds. Stuart Hall et al. Cambridge: Polity Press, 1992.

López Campaña, Perfecto, dir. El libro del Centenario del Uruguay, 1825-1925. Montevideo: Agencia Publicidad Capurro \& Cía., 1925.

Nin y Silva, Celedonio. La República Oriental del Uruguay en su primer centenario (1830-1930). Montevideo: Sureda, 1930.

Ricoeur, Paul. La memoria, la historia, el olvido. Buenos Aires: Fondo de Cultura Económica, 2004.

Rodríguez, Hernán. Revolviendo los escombros del pasado: usos del pasado e identidad en el discurso de los letrados negros de Montevideo (1872-1901). Tesis de maestría, FHCE, Universidad de la República (Uruguay), 2018.

Scuro Somma, Lucía, coord. Población afrodescendiente y desigualdades étnicoraciales en Uruguay. Montevideo: PNUD, 2008.

\section{Fuentes}

Suárez Peña, Lino. Apuntes y datos referentes a la raza negra en los comienzos de su vida en esta parte del Plata. Jun. 19, 1924. Manuscrito. Museo Histórico Nacional, Montevideo.

\section{Publicaciones periódicas}

La Conservación [Montevideo, 1872]

Mundo Uruguayo [Montevideo, 1924]

Nuestra Raza [Montevideo, 1933-1948] 